\title{
H. STAMMREICH AND THE TRIPLE ALLIANCE: THE MOLECULE, THE PROBLEM AND THE INSTRUMENT
}

\author{
Jayr H. Marina, ${ }^{\text {,(1) Douglas S. Lopes }}{ }^{\mathrm{a}}$ and Paulo S. Santos*,a,(1) \\ aDepartamento de Química Fundamental, Instituto de Química, Universidade de São Paulo, 05508-000 São Paulo - SP, Brasil
}

Recebido em 27/05/2019; aceito em 28/08/2019; publicado na web em 21/10/2019

\begin{abstract}
Almost 60 years ago $\mathrm{H}$. Stammreich obtained the Raman spectra of two photosensitive molecules, $\mathrm{CI}_{4}$ and $\mathrm{SnI}_{4}$, using a pioneering technology developed by him. At the time the excitation source was homemade gas lamps. The same experiments were repeated by us, with the best technology available, with outstanding correlation, and some new information was obtained that wasn't possible 60 years ago. The major difference between the experiments was the use of laser, that made the Raman spectroscopist's life much easier and less time-consuming.
\end{abstract}

Keywords: H. Stammreich; Raman spectra; tin tetraiodide; carbon tetraiodide.

\section{INTRODUCTION}

Carbon tetraiodide and tin tetraiodide, whose Raman spectra were investigated by $\mathrm{H}$. Stammreich almost 60 years ago, are highly symmetrical molecules with chemical bonds strongly polarizable what implies very high Raman intensities. Besides both molecules, but mostly the former, are light-sensitive what precludes obtaining the Raman spectra at wavelengths shorter than ca. $600 \mathrm{~nm}$. Given that Stammeinch laboratory was a pioneer and one of the few to use long-wavelength excitation, such molecules were ideal for a Raman study using his instrumentation. It should also be considered that in both molecules there are normal modes that appear at very low frequencies, of the order of $100 \mathrm{~cm}^{-1}$ or lower and their detection demands a Raman instrument capable to reach a region very close to the Rayleigh wing.

Group IV tetrahalides were the object of several studies and, in particular, two previous publications deserve special attention since they were published before and after Stammreich paper. Woodward and Long ${ }^{1}$ investigated the Raman intensities of $\mathrm{MCl}_{4}(\mathrm{M}=\mathrm{C}, \mathrm{Si}$, $\mathrm{Ge}$ and $\mathrm{Sn})$ and $\mathrm{XBr}_{4}(\mathrm{X}=\mathrm{C}$ and $\mathrm{Sn})$, using as excitation $\mathrm{Hg}$ lamp and photographic detection. $\mathrm{CI}_{4}$ and $\mathrm{SnI}_{4}$ were excluded due to their photosensitivity. The main focus of this work was the verification of the relation between bond polarizability and Raman intensity, as predicted by Placzek theory. ${ }^{2}$ It is expected that Placzek theory is a very good approximation for the calculation of Raman intensities, provided that the vibrational mode in question is the symmetrical stretching of spherically symmetrical molecules, such as the group IV tetrahalides, and provided that excitation is far from resonance. On the other hand a resonance Raman study on the carbon, silicon, germanium and tin tetraiodides was performed by Clark and Dines, ${ }^{3}$ using several laser excitation lines in the visible and ultraviolet. In this paper the authors comment on Stammreich's publication on carbon tetraiodide, and highlighted the photo instability of $\mathrm{CI}_{4}$ in wavelengths shorter than c.a. $570 \mathrm{~nm}$. The aggrement of Stammreich Raman shifts for $\mathrm{CI}_{4}$ and those reported by Clark and Dines is perfect within $1 \mathrm{~cm}^{-1}$. The assignment proposed is also the same as previously done by Stammreich et al., which is remarkable taking into account the homemade equipment with photographic detection and He lamp excitation as compared with spectra obtained in a double monochromator, laser excitation and photomultiplier detection. It should be pointed out that the main focus of Clark and Dines was to

*e-mail: pssantos@iq.usp.br investigate the resonance Raman effect in group IV tetrahalides using several visible and UV laser lines. In the case of $\mathrm{SnI}_{4}$, excitation at resonance resulted in the observation of several overtones of the $v_{1}$ mode up to $9 v_{1}$. For $\mathrm{CI}_{4}$ such investigation was not possible due to the extreme photosensitivity in lower wavelengths.

Concerning relative intensities and bandwidths the comparisons are much more difficult since the photographic plate is not linear with respect to recording intensities, and linewidths depend strongly on resolution and, in the case of solutions, on the solvents used. Such parameters can be accurately determined in present days, but were out of the reach of the older instrumentation.

Concerning the comparison of the spectral resolution reported in Stammreich papers, $0.8 \mathrm{~cm}^{-1}$, with those in Clark and Dines where the spectral resolution is reported as c.a. $5 \mathrm{~cm}^{-1}$. These figures can seem odd at first sight. In fact, $0.8 \mathrm{~cm}^{-1}$ was the limit resolution attainable, but the width of the Raman lines for samples in condensed phase is much higher, implying that the effective resolution was of the order c.a. $5-7 \mathrm{~cm}^{-1}$.

Concerning Raman bands below $100 \mathrm{~cm}^{-1}$, recorded by Stammreich for $\mathrm{CI}_{4}\left(90 \mathrm{~cm}^{-1}\right)$ and $\mathrm{SnI}_{4}\left(47\right.$ and $\left.62 \mathrm{~cm}^{-1}\right)$, assigned to bending modes that show up at such low-frequency region given the presence of heavy atoms and low force constants. Reaching such low-frequency region using a spectrograph is another indication of the excellent optical design of Stammreich instrumentation. With present-day instrumentation, at the state of the art, it is possible to reach even lower frequencies, as it'll be shown in what follows. The assignment of such bands is not so straightforward since, in the case of solids, such region is the one where lattice modes are expected. Such modes are expected to disappear in the spectrum of the solution.

Taking into account that over the last 60 years enormous progress in Raman instrumentation has occurred, a question applies: is the quality of the Raman spectra of such molecules obtained with state of the art instrumentation qualitatively different from the ones obtained by Stammreich and coworkers? The present work aims to answer such question.

\section{EXPERIMENTAL SECTION}

Carbon tetraiodide was purchased from Sigma-Aldrich and used as received. Tin tetraiodide was synthesized combining elemental iodine and elemental tin, in a molar ratio of $2: 1$, in hexane. The solution was kept under reflux until an orange solid appeared. For further purification, the solid was recrystallized in hexane. 
The Raman spectra were obtained with the samples in the solid state in a Horiba-Jobin-Yvon T64000 triple monochromator spectrometer equipped with a CCD, using a backscattering geometry. Excitation source was provided by an diode laser Cobalt Flamenco ${ }^{\mathrm{TM}}$ 200 of $660 \mathrm{~nm}$ with a typical output power of $380 \mathrm{~mW}$. The spectrometer is coupled to a microscope, what greatly increases the power density at the sample; the power was ca. $10 \mathrm{~mW}$. An optical slit of $100 \mu \mathrm{m}$ was used to give a spectral resolution of approximately $0.8 \mathrm{~cm}^{-1}$. The exposure time for $\mathrm{CI}_{4}$ was $10 \mathrm{~s}$, and for $\mathrm{SnI}_{4}$ was $5 \mathrm{~s}$.

It is important to mention that photodecomposition was not observed since there was no modification of the image observed in the microscope. In this experimental setup it was possible to observe the Raman spectra down to $10 \mathrm{~cm}^{-1}$.

In the spectra reported by Stammreich et al. frequencies down to ca. $50 \mathrm{~cm}^{-1}$ are reported as compared to ca. $10 \mathrm{~cm}^{-1}$ we observed. It must be emphasized that the instrument used in the present paper is a triple monochromator in the subtractive mode, where the first stage is a filter permitting to reach wavenumbers very close to the Rayleigh wing. In Stammreich instrumentation a spectrograph was used with just one stage.

\section{RESULTS AND DISCUSSION}

The Raman spectrum of $\mathrm{CI}_{4}$, obtained in the present work, is shown in figure 1 . The Raman wavenumbers are listed in table 1 together with the obtained by Stammreich et $a l .{ }^{4}$ As can be seen the aggrement is remarkable. It should be mentioned that in the investigation of Clark and Dines ${ }^{3}$ involving the Raman spectra of tetraiodides of group IV elements the aggrement is also remarkable with Stammreich results, including the assigment of the observed bands.

The Raman spectrum of $\mathrm{SnI}_{4}$ is shown in Figure 2. The Raman wavenumbers are listed in table 2 together with the obtained by

Table 1. Table of frequencies of $\mathrm{CI}_{4}$

\begin{tabular}{ccc}
\hline $\begin{array}{c}\text { Stammreich } \text { et al. }(1961) \\
\text { Exposure time: ca. } 4 \mathrm{~h}\end{array}$ & $\begin{array}{c}\text { Our results } \\
\text { Exposure time: } 10 \mathrm{~s}\end{array}$ & Assigment \\
\hline $90 \mathrm{~cm}^{-1}$ & $89 \mathrm{~cm}^{-1}$ & $\mathrm{v}_{2}(\mathrm{e})$ \\
$123 \mathrm{~cm}^{-1}$ & $123 \mathrm{~cm}^{-1}$ & $\mathrm{v}_{4}\left(\mathrm{f}_{2}\right)$ \\
$178 \mathrm{~cm}^{-1}$ & $179 \mathrm{~cm}^{-1}$ & $\mathrm{v}_{1}\left(\mathrm{a}_{1}\right)$ \\
\hline
\end{tabular}

Stammreich et al. ${ }^{5}$ As can be seen the aggrement is remarkable. Again, it should be mentioned that in the investigation of Clark and Dines ${ }^{3}$ involving the Raman spectra of tetraiodides of group IV elements the aggrement is also remarkable with Stammreich results, including the assigment of the observed bands.

Table 2. Table of frequencies of $\mathrm{SnI}_{4}$

\begin{tabular}{ccc}
\hline $\begin{array}{c}\text { Stammreich et al. (1956) } \\
\text { Exposure time: ca. 10 min }\end{array}$ & $\begin{array}{c}\text { Our results } \\
\text { Exposure time: } 5 \mathrm{~s}\end{array}$ & Assigment \\
\hline $47 \mathrm{~cm}^{-1}$ & $52 \mathrm{~cm}^{-1}$ & $\mathrm{v}_{2}(\mathrm{e})$ \\
$62 \mathrm{~cm}^{-1}$ & $64 \mathrm{~cm}^{-1}$ & $\mathrm{v}_{4}\left(\mathrm{f}_{2}\right)$ \\
$149 \mathrm{~cm}^{-1}$ & $147 \mathrm{~cm}^{-1}$ & $\mathrm{v}_{1}\left(\mathrm{a}_{1}\right)$ \\
$216 \mathrm{~cm}^{-1}$ & $216 \mathrm{~cm}^{-1}$ & $\mathrm{v}_{3}\left(\mathrm{f}_{2}\right)$ \\
\hline
\end{tabular}

Another point to be compared concerns the exposure time for the obtention of the spectra: in the case of $\mathrm{SnI}_{4}$ was about 30 minutes in Stammreich spectrum and about 5 seconds in our case. It should be pointed out that in the former case the spectrum obtained was of a concentrated solution in $\mathrm{CS}_{2}$ and our spectrum was of the sample in the solid-state. In the case of $\mathrm{CI}_{4}$, Stammreich spectrum was recorded with up to 15 hours of exposure, due to the extreme photosensitivity of the sample, what required a continuous renovation of the sample.

One of the difficulties in obtaining the Raman spectra of $\mathrm{CI}_{4}$ and $\mathrm{SnI}_{4}$ is the presence of bands at rather low wavenumbers, as for instance a band at ca. $47 \mathrm{~cm}^{-1}$ in the spectrum of $\mathrm{SnI}_{4}$, since the Rayleigh wing would preclude the accurate measurement. In this respect Stammreich et al. were able to record a Raman band at ca. $47 \mathrm{~cm}^{-1}$, that is the lowest wavenumber assignable to a normal mode of $\mathrm{SnI}_{4}$. With our equipment, in the triple monochromator configuration, it was possible to reach about $10 \mathrm{~cm}^{-1}$. The comparison with the spectrum obtained by Stammreich et al. shows how close to the Rayleigh wing they could get, what is remarkable since the equipment used was a single stage spectrograph.

The instrumentation developed by Stammreich and coworkers was to a great extent homemade. It is important to know several details that normally are not reported in their papers. Fortunatelly most of such details were reported in a publication that is an example of the state of the art of experimental spectroscopy at those days. ${ }^{6}$ It is

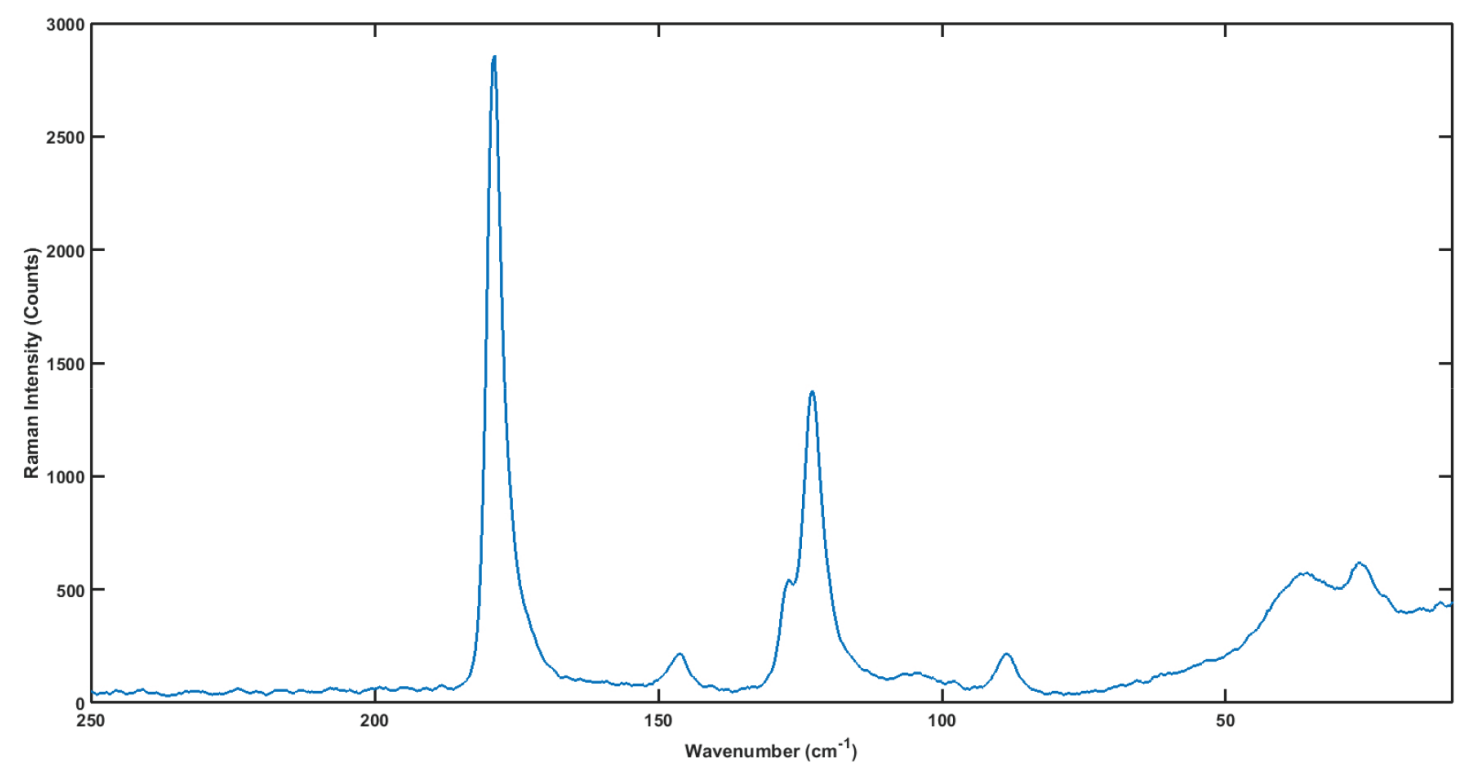

Figure 1. Raman spectrum of carbon tetraiodide within the region of 10 to $250 \mathrm{~cm}^{-1}$ 


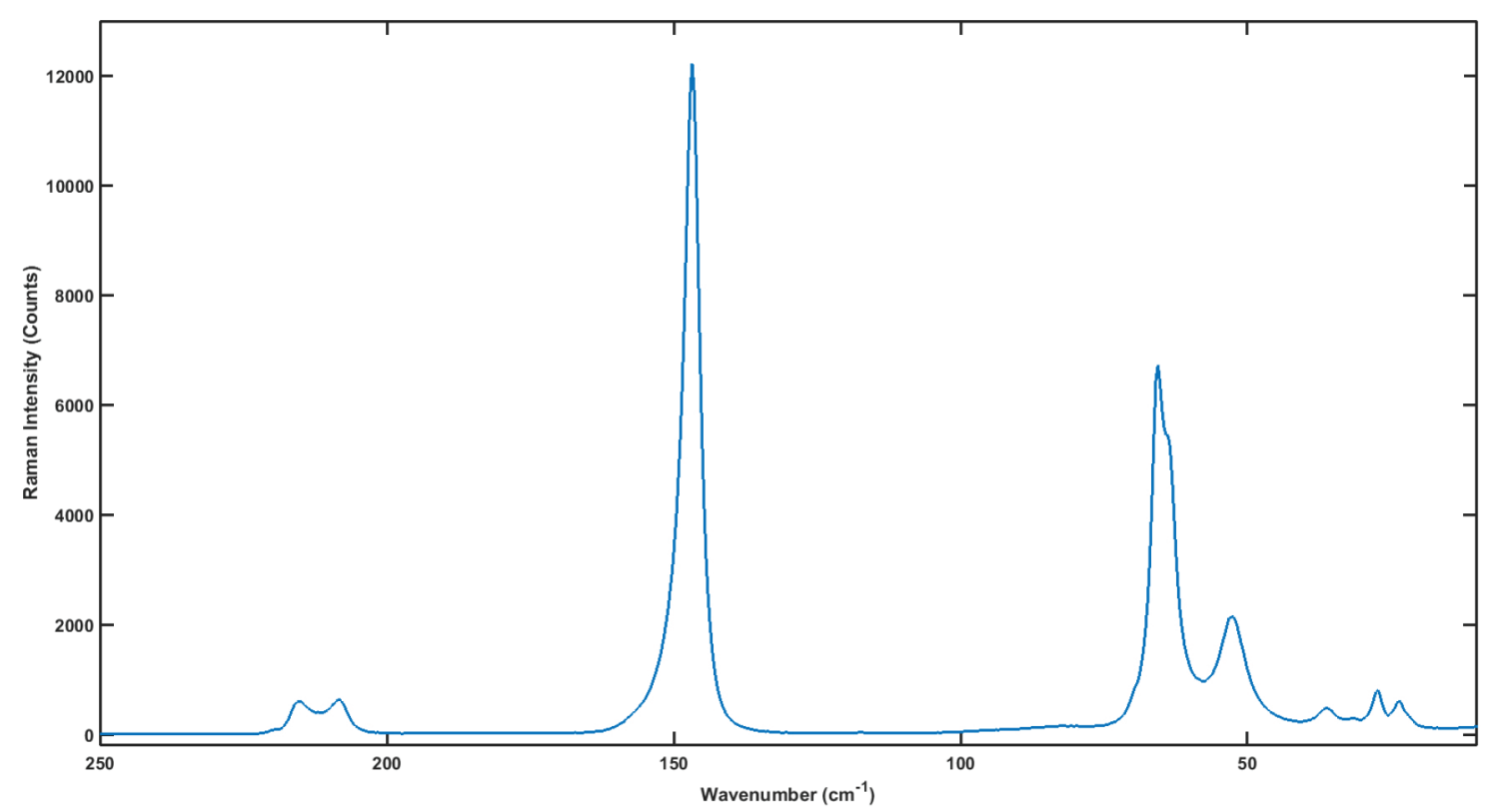

Figure 2. Raman spectrum of tin tetraiodide within the region of 10 to $250 \mathrm{~cm}^{-1}$

highly recommended for those interested in the evolution of Raman spectroscopy instrumentation over the years.

\section{CONCLUSIONS}

Taking into account that the spectra were obtained more than 60 years ago by $\mathrm{H}$. Stammreich et al., the agreement is outstanding. The use of lasers and other technologies changed the entire scenario of Raman spectroscopy, but one should not forget that the pionering methods developed by $\mathrm{H}$. Stammereich were very important by that time. Despite the enormous advances in instrumentation over the years, the reading of Stammreich papers shows a very carefull analysis of the results, what is becoming increasingly rare at present days.

\section{AGRADECIMENTOS}

Thanks to Prof. M. C. C. Ribeiro for the help in obtaining the Raman spectra in the Horiba-Jobin-Yvon T64000 spectromether.

\section{REFERÊNCIAS}

1. Woodward, L. A.; Long, D. A.; Trans. Faraday Soc. 1949, 45, 1131.

2. Placzek, G.; Rayleigh-Streuung und Raman-Effekt, Akademische Verlagsgesellschaft: Leipzig, 1934.

3. Clark, R. J. H.; Dines, T. J.; Inorg. Chem. 1980, 19, 1681.

4. Stammreich, H.; Tavares, Y.; Bassi, D.; Spectrochim. Acta 1961, 17, 661.

5. Stammreich, H.; Forneris, R.; Tavares, Y.; J. Chem. Phys. 1956, 25, 1278.

6. Stammreich, H.; Forneris, R.; Spectrochim. Acta 1961, 17, 775.

FAPESP helped in meeting the publication costs of the article 